\title{
Topical collection on the influence of Intelligent Transport Systems on vulnerable road user accidents
}

\author{
Johan Scholliers
}

There are several definitions for the term "Vulnerable road users". In the definition of Eisses [1], vulnerability is associated to different aspects, including the absence of a protective cage such as pedestrians, cyclists and Powered Two-Wheelers (PTW), physical vulnerability (elderly, children, disabled), the lack of skills to safely participate in traffic (persons with little driving experience, elderly drivers) and sub-optimal traffic behaviour and attitude of the participant (e.g. drunken driving).

During the past decade substantial progress has been made in improving road safety. Between 2006 and 2015 the total number of road fatalities has been reduced by $40 \%$, however the reduction has been less for VRUs (pedestrians $36 \%$, cyclists $27 \%$, motorcycles $28 \%$, mopeds 57\%) [2]. The total share of VRUs in road fatalities in the EU is $46 \%$, with pedestrians $21 \%$ and PTW riders and occupants 18\% [2]. During the past years the decrease for all road users is stagnating, and the European Commission has issued a Strategic Action Plan on Road Safety [3].

One of the potential measures to improve traffic safety is through the use of ITS (Intelligent Transport Systems), by making the vehicle or the infrastructure more intelligent. The main focus in the previous decades has been on improving the safety of vehicles through various passive and active systems, such as Advanced Driver Assistance Systems (ADAS). Collisions with VRUs are addressed through improvement of detection of VRUs and through reducing the impact of collisions with VRUs. In order to be able to improve the safety of all VRUs, a more holistic approach is needed, which involves all stakeholders, including vehicle manufacturers, national and local authorities and road user representatives.

This Topical Collection contains five papers based on the research conducted in the project Vulnerable Road Users using Intelligent Transport Systems (VRUITS),

Correspondence: johan.scholliers@vtt.fi

VTT Technical Research Centre of Finland Ltd, P.O.Box 1300, 33101 Tampere, Finland

(c) The Author(s). 2018 Open Access This article is distributed under the terms of the Creative Commons Attribution 4.0 International License (http://creativecommons.org/licenses/by/4.0/), which permits unrestricted use, distribution, and reproduction in any medium, provided you give appropriate credit to the original author(s) and the source, provide a link to the Creative Commons license, and indicate if changes were made. which was co-funded by the European Commission in the 7th Framework Programme, and lasted from April 2013 to March 2016. The main object of the VRUITS project was to research how Intelligent Transport Systems can contribute to improve the safety, mobility and comfort of Vulnerable Road Users. The accident analysis performed in the VRUITS project focused on specific road user types for which statistics are available: pedestrians, cyclists and PTW riders, which include low speed scooters, mopeds and motorcyclists, are treated as separate groups. The VRUITS project started by identifying the most critical traffic scenarios for VRUs, through analysis of both European accident databases, such as CARE, and national databases [4]. For pedestrians, the most critical scenarios for pedestrians are crossing the road at mid-block. For cyclists and PTWs, the most critical scenarios are intersection scenarios, when the vehicle pulls out into the path of an oncoming VRU or turns into the VRU's path.

ITS systems add intelligence to either the vehicle, the infrastructure or the VRU. Vehicle ITS systems, which were shown to have a high safety potential, include autonomous emergency braking (AEB) systems with pedestrian (and cyclist) detection and blind spot detection systems. Euro NCAP currently has already since 2016 introduced scenarios for pedestrian AEB, both at daylight and in darkness, and since 2018 also addresses AEB for cyclists. In May 2018, the European Commission suggests to make 11 safety systems mandatory for new vehicles, including Automated Emergency braking with pedestrian and cyclist detection, and VRU detection at blind spots for trucks [3].

Also the infrastructure can be made more intelligent. At signalised intersections, sensors detecting pedestrians at or near crosswalks can be used in the control of the traffic lights, providing safe crossing to elderly pedestrians and persons with special needs, and optimising green time phases for all road users. Sensors, detecting cyclists approaching crossings, could be used to provide

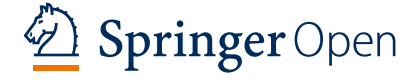


green waves to cyclists. When providing signal phase information to cyclists, they can adapt their speed in order to pass through green.

In the last decade, much research has been performed on V2X technology, in which vehicles exchange information with each other and with the infrastructure. The first wide scale deployments of V2X will come on the market in 2019. Vulnerable Road Users are only in a very limited extend included in the services which will first come to the market. However, by also equipping VRUs or their vehicles with the technology, road users can be made aware of potential conflicts before visual contact.

The five papers in this Topical Collection deal with several issues related to the impact of ITS on vulnerable road users. Scholliers et al. [5] describe the how VRUs can be integrated in cooperative ITS systems. There are many potential configurations: VRUs or their vehicles can be equipped with a device which has unidirectional or bidirectional communications, or the VRUs - having no own device - are detected by the infrastructure or other road users. The paper describes the architecture which has been developed for cooperative ITS systems including VRUs, describes the major issues regarding the devices for VRUs and provides a roadmap towards deployment of cooperative ITS services for VRUs.

Malone et al. [6] describe the assessment methodology, which was developed to assess the potential impact on safety, comfort and mobility of VRUs. The methodology, which was used in the VRUITS project, is based on the method introduced by Kulmala [7], which was developed for assessing the safety impact of ITS for cars. This method utilises a set of nine mechanisms via which ITS can affect road user behaviour and thereby road safety, which cover the three aspects of road safety in a systematic manner and are based on a ten-point list compiled by Draskóczy et al. [8], and hence including both direct and indirect effects, and short term and long term effects.

The methodology described by Malone et al. [6] has been used for the assessment of 10 ITS systems within the VRUITS project. Starting from an inventory of potential ITS systems, and discussions with stakeholders, a set of 23 potential systems which have the potential to improve VRU safety or mobility were selected for further assessment [4]. After a qualitative assessment of these ITS systems, a set of 10 systems were withheld for a quantitative safety, mobility and comfort assessment as well as cost-benefit analysis.

Silla et al. [9] describe the application of the safety assessment methodology for 3 cooperative ITS systems for PTW riders: Intersection Safety (relying on I2V communications from the infrastructure to vehicles), PTW oncoming vehicle information systems (bidirectional PTW2V communications) and VRU beacon system (unidirectional communication from PTW to vehicles). The paper shows that these cooperative ITS have a positive impact on PTW rider safety by preventing fatalities and injuries.

Based on the results of the research performed in VRUITS and discussions with stakeholders a set of recommendations for policy and industry were formulated. Mans et al. [10] describes the methodology for drawing a set of recommendations for actions at EU level. The work started by identifying the barriers, drawing a list of potential recommendations, prioritising the list and then performing a quantitative Benefit analysis and multi-criteria analysis on a set of 13 main recommendations. The paper reports also the recommendations of the VRUITS project, related to improving the performance of the systems. Most of the challenges are related to technical issues or requiring the collaboration of a wide set of stakeholders.

In the past few years the focus in automotive related ITS research has shifted towards automated driving and autonomous vehicles. The assumption is that by automating vehicles human errors, which are often the cause of accidents, can be eliminated and hence a future, in which no person dies in traffic accidents, could be realised. Autonomous driving is made possible through developments in Artificial Intelligence technology. This involves the collection of a wide amount of data, including all potential traffic environments and environmental conditions. A main issue with VRUs is their wide variety, e.g. pedestrians with strollers, cyclists. A huge effort will be needed to be able to detect reliably pedestrians in all potential traffic and environmental conditions. And the problem is even larger for identifying cyclists, as was reported by Fairley [11]. The issue was also painfully demonstrated in the first fatal accident with automated vehicles when an Uber vehicle in automated mode had problems to classify correctly a pedestrian walking with a bike and to make the correct collision avoidance action [12].

The same comment, which was made in the start of this editorial, regarding the research on ITS, is also valid for automated vehicles: research and development is mainly concentrated on the vehicles, with VRUs as objects which should be detected and avoided. The interaction between VRUs and vehicles are only little covered in research. In current traffic, vehicle and pedestrian interaction depends both on many nonverbal cues from the driver and the vehicle, such as eye contact and vehicle speed and distance. These cues are not valid anymore when the driver is not in control of the vehicle. Research work on the interaction between automated vehicles and pedestrians has recently been taken up, e.g. $[13,14]$ Habibovic et al. [14] showed that an external vehicle interface, showing the intent of the automated vehicle, improves the perceived safety of pedestrians. Cyclists and motorcyclists have much higher speeds than pedestrians, and hence there is less time between their 
detection and the required corrective actions by vehicle and/or VRU. V2X technology allows to increase the detection range, can be enhanced, allowing to improve the safety of both road users improved.

Automated transport can make transport more accessible and increase the comfort for persons with special needs and for the growing amount of elderly drivers. The evolution towards a more connected and automated transport system opens new possibilities for increasing the safety and comfort of road users. Fully automated transport allows persons, which are now not capable of driving, such as impaired and elderly persons, to access personal vehicles and hence increases their mobility and the comfort.

A lot of questions remain however, especially how automated vehicles will interact with VRUs, and how the future transport system will look like: will conventional personal cars be replaced with personally owned automated vehicles, or will the current fleet be replaced by a smaller shared fleet? Will fully automated vehicles be able to drive on all roads or will they be restricted to specific areas, with only limited interactions to VRUs. The requirements set by automated vehicles to the traffic infrastructure are still unclear. Some visionaries claim that traffic signals will not be needed anymore, as vehicles can talk and negotiate with each other, but in these visions the VRU seems to be forgotten. Automated vehicles are an exciting subject, and have the potential to improve the safety of all road users, but there is still a long road ahead.

\section{Author's contribution}

The author read and approved the final manuscript.

\section{Competing interests}

The author declares that he has no competing interests.

\section{Publisher's Note}

Springer Nature remains neutral with regard to jurisdictional claims in published maps and institutional affiliations.

Received: 29 November 2018 Accepted: 29 November 2018

Published online: 14 December 2018

\section{References}

1. Eisses, S. (2011). ITS Action Plan, D4 - Final Report - Action 3.4 - Safety and Comfort of the Vulnerable Road User, Framework Service Contract TREN/G4/FV2008/475/01.

2. European Road Safety Observatory (2017) Annual Accident Report 2017. https://ec.europa.eu/transport/road_safety/sites/roadsafety/files/pdf/ statistics/dacota/asr2017.pdf.

3. European Commission (2018) Strategic action plan on road safety, COM(2018) 293 final, Annex 1. https://eur-lex.europa.eu/resource.html?uri= cellar:0e8b694e-59b5-11e8-ab41-01aa75ed71a1.0003.02/DOC_2\&format=PDF

4. Scholliers, J., Bell, D., Morris, A., Garcia Melendez, A. B., \& Martin Perez, O. (2016). Improving safety and mobility of Vulnerable Road Users through ITS applications. In G. Yannis \& S. Cohen (Eds.), Traffic Safety (Vol. 4, pp. 251-269). Wiley-ISTE. https://www.wiley.com/en-us/Traffic+Safety-p-9781786300300

5. Scholliers, J., van Sambeek, M., \& Moerman, K. (2017). Integration of vulnerable road users in cooperative ITS systems. European Transport Research Review, 9, 15.

6. Malone, K., Silla, A., Johanssen, C., \& Bell, D. (2017). Safety, mobility and comfort assessment methodologies of Intelligent Transport Systems for vulnerable road users. European Transport Research Review, 9, 21. https://doi. org/10.1007/s12544-017-0235-y.

7. Kulmala, R. (2010). Ex-ante assessment of the safety effects of Intelligent Transport Systems. Accident Analysis and Prevention, 42, 1359-1369.

8. Draskóczy, M., Carsten, O.M.J. \& Kulmala, R. (Eds.) (1998) Road safety guidelines. CODE Project, Telematics Application Programme, Deliverable B5.2.

9. Silla, A., Leden, L., Rämä, P., Scholliers, J., van Noort, M., Morris, A., Hancox, G. \& Bell, D. (2018). A headway to improve PT rider safety within the EU through 3 types of ITS. European Transport Research Review, 10, 18.

10. Mans, D., Giannelos, I., van Breemen, R., Rood, M., Silla, A., Rämä, P., Scholliers, J., Martin Perz, O., \& Malone, K. (2017). Recommendations for actions concerning supporting ITS developments for VRUs. European Transport Research Review, 9, 22.

11. Fairley, P. (2018). The self-driving car's bicycle problem. IEEE Spectrum, 31(1), 2018 https://spectrum.ieee.org/cars-that-think/transportation/self-driving/ the-selfdriving-cars-bicycle-problem.

12. NTSB (2018) Preliminary report Highway HWY18MH010, https://www.ntsb. gov/investigations/AccidentReports/Reports/HWY18MH010-prelim.pdf

13. Rasouli, A., \& Tsotsos, J. (2018). Autonomous Vehicles that Interact with Pedestrians: A Survey of Theory and Practice, submitted to the IEEE Transactions on Intelligent Transportation Systems.

14. Habibovic, A., Lundgren, V. M., Anderson, J., Klingegård, M., Lagström, T., Sirkka, A., Fagerlönn, J., Edgren, C., Fredriksson, R., Krupenia, S., Saluäär, D., \& Larsson, P. (2018). Communicating intent of automated vehicles to pedestrians. Frontiers in Psychology, 9, 1336.

\section{Submit your manuscript to a SpringerOpen ${ }^{\circ}$ journal and benefit from:}

- Convenient online submission

- Rigorous peer review

- Open access: articles freely available online

High visibility within the field

- Retaining the copyright to your article

Submit your next manuscript at $\boldsymbol{\nabla}$ springeropen.com 